\title{
Experimental Economics: Where Next? Rejoinder
}

\author{
by Ken Binmore and Avner Shaked
}

Our paper "Experimental Economics: Where Next?" contains a case study of Ernst Fehr and Klaus Schmidt's work in which it is shown that the claims they make for the theory of inequity aversion are not supported by their data. The current issue of JEBO contains two replies, one from Fehr and Schmidt ${ }^{1}$ themselves, and the other from Catherine Eckel and Herb Gintis.

Neither reply challenges any claims we make about matters of fact in our critique of Fehr and Schmidt on inequity aversion, although it is clear that if they could have refuted any single factual sentence then they would have done so. Both replies therefore implicitly concede that the facts quoted in our case study are correct. All the other issues raised in the two replies are just so much dust kicked up to distract attention from the only question that matters: Is it scientific to proceed like Fehr and Schmidt or is it not?

Fehr and Schmidt say yes. So do Eckel and Gintis. The implications are quite far-reaching for those like us who think it is obvious that the answer is no. What other claims asserted by the school of Gintis et al can we trust?

For example, Gintis makes the theory of inequity aversion one of the twin pillars of laboratory wisdom in his forthcoming book, The Bounds of Reason (Gintis, 2009, Chapter 3). He is even more fulsome when addressing sociologists in a joint paper with Fehr (Fehr and Gintis 2007, page 60):

Formal models, such as those of inequity aversion (Fehr and Schmidt 1999) and reciprocal fairness (Falk and Fischbauer 2006) are indispensable tools of social analysis. We would not have been able to pierce the bewildering puzzles posed by the experimental regularities without the help of such models.

As this quote indicates, Gintis's second pillar of laboratory wisdom is strong reciprocity. But is the experimental evidence that supports strong reciprocity

\footnotetext{
${ }^{1}$ Fehr and Schmidt's reply implies that we have no criticisms to make of their work beyond those listed in our paper. In particular, they assert that criticisms made in Shaked's (2005) "Rhetoric of Inequity Aversion" have been withdrawn. In fact, the criticisms in our paper are a selection from a much longer list, including several we had overlooked that were spotted by an alert referee.
} 
(rather than weak reciprocity) any more solid than the evidence that supports inequity aversion?

The facts on the ground seem to count for nothing with Gintis et al when they run counter to what they regard as received wisdom. Eckel and Gintis even question the best established and most replicated results in experimental economics: namely those on Public Goods Games like the one-shot Prisoners' Dilemma. In the latter game, somewhat less than fifty percent of inexperienced subjects defect, but around ninety percent or so of experienced subjects end up defecting after about ten trials. Presumably Eckel and Gintis feel that more other-regarding behavior should have been observed, and therefore it is acceptable to cast doubt on literally hundreds of experiments in which similar results have been replicated. We urge readers to check up on this vital matter by looking, for example, at Ledyard (1995), Camerer (2003, page 46), or and Faschbauer and Gächter (2008).

We are not hostile to experimental work as Eckel and Gintis assert. Nor are we mindless defenders of neoclassical economics. We believe that social preferences and social norms are real phenomena that have been too long neglected. But no scientific progress is likely on these vital issues if we continue to allow ourselves to be convinced by the superlative public relations of the school of Gintis et al, without first checking up on the data from which their claims are supposedly deduced.

\section{References}

C. Camerer, C. (2003) Behavioral Game Theory: Experiments in Strategic Interaction, Princeton University Press, Princeton.

A. Falk and U. Fischbauer (2006) "A Theory of Reciprocity", Games and Economic Behavior 54: 293-315.

U. Faschbauer and S. Gächter (2008) "Heterogeneous Social Preferences and the Dynamics of Free-Riding in Public Goods Games", CeDEx discussion paper, Nottingham University.

E. Fehr and H. Gintis 2007, "Human Motivation and Social Cooperation: Experimental and Analytic Foundations" Annual Review of Sociology 33: 43-64.

E. Fehr and K. Schmidt (1999) A Theory of Fairness, Competition and Cooperation. Quarterly Journal of Economics 114, 817-868. 
H.Gintis (2009) The Bounds of Reason: Game Theory and the Unification of the Behavioral Sciences, forthcoming with Princeton University Press.

J. Ledyard (1995) "Public Goods: A Survey of Experimental Research", in Handbook of Experimental Economics eds. J. Kagel and A. Roth, Princeton University Press, Princeton.

A. Shaked (2005) "The Rhetoric of Inequity Aversion". See http://www.najecon.org/naj/cache/666156000000000612.pdf 